\title{
Seasonality, abundance, and fifteen-year trend in green turtle nesting activity at Itsamia, Moheli, Comoros
}

\author{
J. Bourjea ${ }^{1,2, *}$, M. Dalleau ${ }^{3}$, S. Derville ${ }^{3,4}$, F. Beudard ${ }^{3,5}$, C. Marmoex ${ }^{3}$, A. M'Soili ${ }^{5}$, \\ D. Roos $^{1}$, S. Ciccione ${ }^{3}$, J. Frazier ${ }^{6}$
}

${ }^{1}$ Institut Français de Recherche pour l'Exploitation de la Mer (Ifremer), Délégation Océan Indien, Rue Jean Bertho, BP 60, 97822 Le Port Cedex, Ile de La Réunion, France

${ }^{2}$ University of Reunion Island, FRE3560 INEE-CNRS, 15 Avenue René Cassin, BP 7151, 97715 Saint Denis, La Réunion, France

${ }^{3}$ Kélonia, l'Observatoire des Tortues Marines de La Réunion, 46 rue du Général De Gaulle, 97436 Saint Leu, La Réunion, France

${ }^{4}$ Ecole Normale Supérieure de Lyon, Département de Biologie, 15 parvis René Descartes, 69007 Lyon, France

${ }^{5}$ Association pour le Développement Socio-Economique d'Itsamia (ADSEI), BP 36, Fomboni, Moheli, Comoros

${ }^{6}$ Division of Amphibians and Reptiles, Department of Vertebrate Zoology, National Museum of Natural History, Smithsonian Institution, PO Box 37012, Washington, DC 20013-7012, USA

\begin{abstract}
Nesting green turtles Chelonia mydas were studied at Moheli Island, Union of Comoros, southwestern Indian Ocean (SWIO). Five contiguous beaches near Itsamia village, in the southeastern part of the island, were monitored daily for nesting activity from January 1999 to June 2007 and irregularly between August 2009 and December 2014; nesting success was recorded from 2000 to 2006. Nesting occurred year-round and peaked in the austral winter, from March through August, with the highest values in May. During the $7 \mathrm{yr}$ period when nesting success was recorded, 63164 successful nestings were reported, and the total was 69630 when estimates of missing data were included. The average rate of nesting success was $0.49(\mathrm{SD}=0.04, \mathrm{n}=$ 7). Using the estimate of 3.03 successful nestings per female per season, the estimated number of nesting females per year varied from 924 in 2000 to 5827 in 2005. There was marked growth in nesting activity over the beginning of the study period, as indicated by seasonal decomposition of time series by loess and generalized additive mixed model analyses, with an increase of $226 \%$ from 1999 to 2006 and evidently a leveling off of nesters between 2007 and 2014. The Itsamia beaches have one of the largest nesting populations, with a higher rate of increase than any other site in the SWIO. Long-term protection of the beaches and offshore waters by the Itsamia community, despite several years of intense exploitation by outsiders, is reasoned to be the primary explanation for these remarkable figures.
\end{abstract}

KEY WORDS: Green turtle $\cdot$ Nesting $\cdot$ Seasonality $\cdot$ Trend $\cdot$ Comoros $\cdot$ Moheli

\section{INTRODUCTION}

Situated at the northern end of the Mozambique Channel, the Comoros Archipelago is composed of 4 main islands: Grande Comore (or 'Ngazidja'), Anjouan (or 'Ndzouani'), Mayotte (or 'Maoré'), and Moheli (or 'Mwali'). Grande Comore is the largest and hosts the capital, Moroni; Anjouan has the greatest human

${ }^{*}$ Corresponding author: jerome.bourjea@ifremer.fr population; and Moheli is the smallest. Mayotte is a French overseas territory, while the other 3 islands form the Union of Comoros. Initial field studies on marine turtles in Comoros were carried out between 1972 and 1985 (Frazier 1975, 1980, 1982, 1984, 1985, Hughes 1982, Fretey \& Fourmy 1996), after which there was a lull for nearly 20 yr. Although Frazier (1985) reported no nesting on Grande Comore or

(C) The authors 2015. Open Access under Creative Commons by Attribution Licence. Use, distribution and reproduction are unrestricted. Authors and original publication must be credited. 
Anjouan, he estimated that about 2000 green turtles nested annually on Moheli, with at least 36 beaches showing nest spoor out of 92 beaches suitable for nesting. At the same time, almost 4 decades ago, Mayotte was thought to host fewer than 600 annual nesters, with 19 beaches showing signs of nesting (Frazier 1985). However, more recently, it has been estimated that more than 2000 females nest annually on just the 2 most important beaches of Mayotte (i.e. Saziley and Moya), and a total of more than 3000 nesters per year are thought to use 82 beaches out of 170 suitable nesting beaches on this island (Bourjea et al. 2007a). Nesting activity on these 2 Comoros islands, as well as other green turtle rookeries in the northern part of the southwestern Indian Ocean (SWIO), shows temporal synchrony (Dalleau et al. 2012).

The consumption of turtle meat is generally common on Grande Comore and Anjouan, but the habit varies among different villages on Mayotte and Moheli. Although nearly all inhabitants of Comoros are Muslim, the consumption habits depend on religious beliefs, demography, and ethnic origin of the village (Lilette 2007). For example, at Itsamia, in southeastern Moheli, the community is Islam shafeite, with a belief system that forbids the consumption of animals that live in 2 different worlds. Hence, marine turtles that live in the water and nest on land are 'haram' (i.e. 'forbidden' and/or 'sacred'), and turtle meat is not consumed and reportedly never was. However, the introduction of motorised boats to the Comoros in the early 1980s allowed the beaches of Itsamia to be easily reached by people from Anjouan and Grande Comore, which resulted in the active exploitation and trade of turtles and their meat, especially reproductive females butchered on the beaches of Itsamia (Lilette 2007).

In 1991, in response to outside disturbance, especially the intense, uncontrolled exploitation of turtles, the inhabitants of Itsamia founded the Association pour le Développement Socio-Economique d'Itsamia (ADSEI, Association for the Socio-Economic Development of Itsamia). Through ADSEI, they took measures to stop turtle poaching at Itsamia, relying on the protection of marine turtles by national legislation as well as by international conventions, of which Comoros is a signatory. This local initiative has been coupled with economic and socio-political development of the village; motivated by the protection of marine turtles, international organisations have provided financial and technical support to construct a communal building (the Turtle House) and tourist bungalows. Of particular importance, in 1999, a partnership between ADSEI, Kélonia (the Marine Turtle Centre of La Réunion), and the Institut Français de Recherche pour l'Exploitation de la Mer (Ifremer) was created, with 2 primary goals: (1) to protect the threatened marine turtles through local awareness campaigns, and (2) to develop income-generating activities such as nature tourism. This partnership also included monitoring of the 5 contiguous nesting beaches that are in the immediate vicinity of Itsamia on the eastern extreme of the island (Fig. 1), a project that began in 1999 and continues to date.

The green turtle Chelonia mydas is a highly migratory, long-lived species with delayed sexual maturity

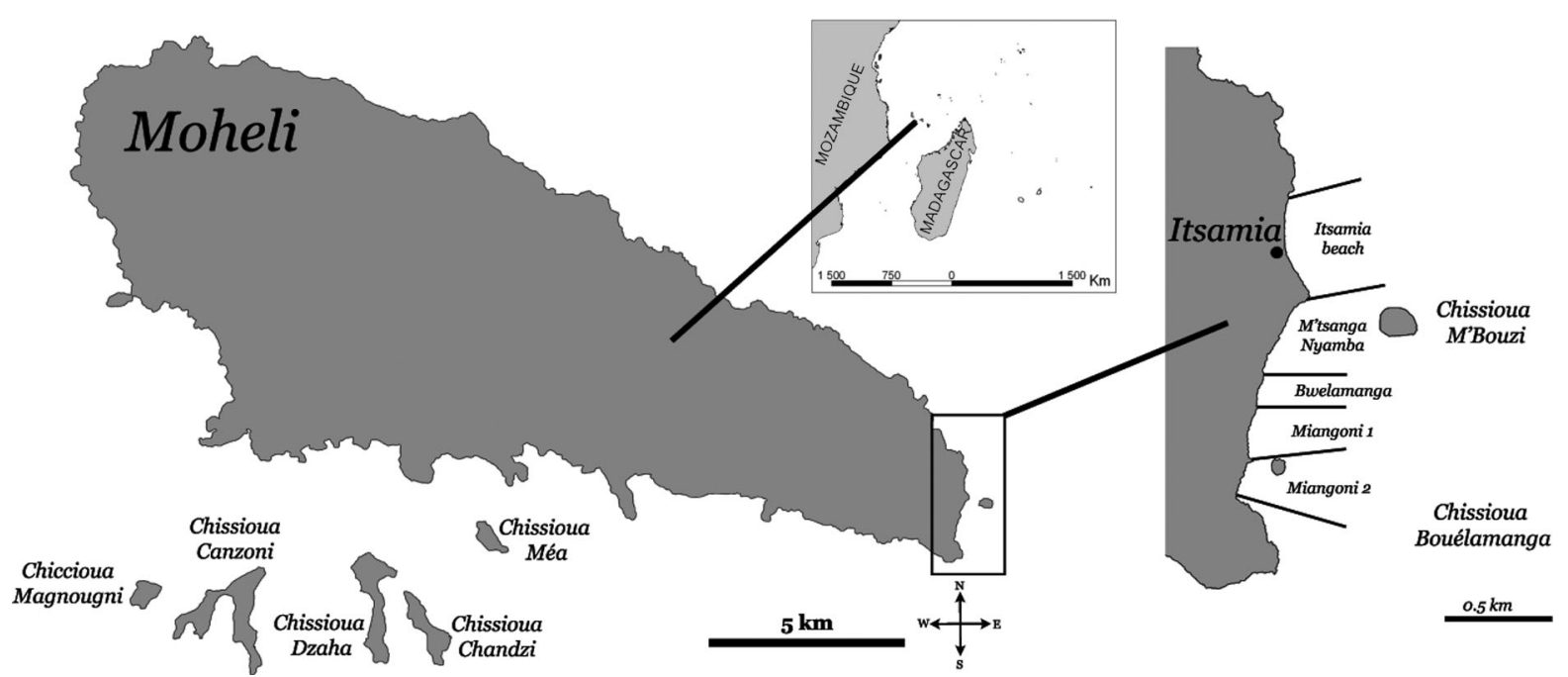

Fig. 1. Moheli $\left(12^{\circ} 18^{\prime} \mathrm{S}, 43^{\circ} 35^{\prime} \mathrm{E}\right)$, smallest of the 4 main islands of the Comoros Archipelago, showing the 5 contiguous beaches (Itsamia beach, M'tsanga nyamba, Bwelamanga, Miangoni 1, and Miangoni 2) that were monitored for tracks (January 1999 to December 2014) and successful nests (January 2000 to December 2006) 
and high adult survival. This species is found circumglobally in tropical and subtropical waters, but in many areas, the green turtle is now regarded as an endangered species. It is listed on the IUCN Red List (www.iucnredlist.org), primarily because of the overexploitation of eggs and adults on nesting beaches as well as bycatch in fisheries and perturbation to both nesting and feeding habitats (Seminoff 2004). Indeed, there is considerable evidence of significant population declines of green turtles over the past few centuries, especially in the Indian Ocean region, most of which is thought to be due to overexploitation and destruction of nesting and foraging habitats (Frazier 1975, 1980, Ciccione \& Bourjea 2006). Nonetheless, the SWIO has hosted some of the world's most important nesting and feeding grounds for green turtles (Frazier 1971, 1975, 1984, 1985, Hughes 1973, Le Gall et al. 1986, Le Gall 1988). This region, defined here as the waters bounded by the eastern coast of Africa extending from Kenya to South Africa and east as far as $60^{\circ} \mathrm{E}$, nowadays includes major green turtle nesting areas such as Europa and Tromelin Islands (Lauret-Stepler et al. 2007), Aldabra Atoll (Frazier 1971, 1984, Mortimer 1985, Mortimer et al. 2011a), and Mayotte (Bourjea et al. 2007a), where each island/atoll regularly hosts thousands of annual nesters. Wallace et al. (2011) identified a single regional management unit for green turtles in the SWIO, and recent genetic research showed that this region hosts at least 3 different genetic management units for this species (Bourjea et al. 2007b, in press). Therefore, population evaluation on other islands of the SWIO, particularly those like Moheli that are thought to host large nesting populations, is essential for estimating population size and trends throughout the region as well as designing and implementing effective conservation measures.

Population assessments of marine turtles are routinely based on indirect counts, or estimates, notably track counts, which in turn are used to estimate the number of nests per season, annual hatchling production, and/or annual egg production (Schroeder \& Murphy 1999, Frazier 2012). Although routinely used to estimate reproductive effort, female abundance, and population size, these estimators are based on several fundamental suppositions. Of particular importance are the assumptions that: (1) the proportion of the total number of tracks that are associated with successful nestings is constant throughout a season, among seasons, and among females; (2) the mean number of successful nests per female per season remains constant; and (3) the detectability of successful nests is reliable and consistent.
The present study documents the nesting activity of green turtles for more than $15 \mathrm{yr}$ at 5 contiguous beaches from southeastern Moheli and assesses nesting seasonality and annual changes in abundance indicators, information that is fundamental for understanding population status and trends to help design effective conservation measures.

\section{MATERIALS AND METHODS}

\section{Study site and data collection}

More than $1.6 \mathrm{~km}$ of beach on the east coast of Moheli (12 $18^{\circ} \mathrm{S}, 43^{\circ} 35^{\prime} \mathrm{E}$, Fig. 1) were monitored for this study. This area, immediately seaward and south of Itsamia village, is composed of 5 contiguous beaches which vary from 160 to $510 \mathrm{~m}$ long: Itsamia beach $(440 \mathrm{~m})$, M'tsanga nyamba $(510 \mathrm{~m})$, Bwelamanga (160 m), Miangoni 1 (310 m), and Miangoni 2 $(210 \mathrm{~m})$ (Fig. 1). These beaches are separated from one another by narrow rocky promontories that are never more than $150 \mathrm{~m}$ wide, and they share similar topography and sand type. The nearest beaches to either side of the 5 Itsamia beaches where green turtles can potentially nest are $1.5 \mathrm{~km}$ to the southwest and $1.6 \mathrm{~km}$ to the northwest, although there is little evidence of nesting on either of these beaches. All 5 Itsamia beaches were monitored daily from 1 January 1999 until 15 June 2007 (8 yr 5.5 mo) to record nesting attempts (tracks) and from 1 January 2000 to 31 December 2006 ( 7 yr) to record successful nestings (Table 1). Additional monitoring occurred opportunistically from 1 August 2009 until 31 December 2014, for a total of 31 months monitored over this period of $5.5 \mathrm{yr}$ (Table 1).

In 1998, Kélonia and Ifremer staff trained 2 ADSEI members in basic field techniques, particularly for monitoring nesting beaches. Track counts, routinely used to estimate nesting abundance (Schroeder \& Murphy 1999), were then calculated from daily observations, following the same protocols described in Lauret-Stepler et al. (2007) and Bourjea et al. (2007a). As not all nesting attempts result in successful nestings (i.e. oviposition), it was necessary to evaluate spoor other than just the tracks, namely to check for signs of a body pit filled in with sand that had been thrown backwards as the female moved out of the cavity after depositing and covering eggs (Schroeder \& Murphy 1999, Frazier 2012). Nonetheless, success at reading turtle nesting signs varies with the experience and skill of the observer; hence, the evaluation of successful nesting on the basis of reading spoor 
Table 1. Summary of beach monitoring results from 1 January 1999 through 15 June 2007 on the 5 contiguous beaches, Itsamia, Moheli, Comoros Archipelago; yearly and average values for 5 contiguous Itsamia beaches combined (Itsamia beach, M'tsanga nyamba, Bwelamanga, Miangoni 1, and Miangoni 2): estimated values were calculated by correcting for missing data by extrapolating (see 'Materials and methods: Missing data'); nest attempts (Ao): sum of tracks divided by 2 for all days that had beach patrols; successful nestings (No): sum of nest attempts that had signs of successful nesting for all days that had beach patrols; effort: effort invested in counting nest attempts and successful nesting in \% of days of the year; total estimated no. of nest attempts: sum of estimated nest attempts per month for all of days of the months; $\hat{r}=$ nesting success, calculated as follows: $\hat{r}=N o \div A o ; \hat{m}=3.03$ is the average number of successful nests per female per season calculated for Mayotte (Bourjea et al. 2007a); total number of turtles nesting per season was estimated by dividing the total number of successful nests estimated per season by $\hat{m}_{i}$ SD: standard deviation. No sampling occurred in 2008. (-) not available

\begin{tabular}{|c|c|c|c|c|c|c|c|c|c|}
\hline Year & $\begin{array}{l}\text { Sampling } \\
\text { period }\end{array}$ & $\begin{array}{l}\text { No. of } \\
\text { months }\end{array}$ & $\begin{array}{l}\text { Nest } \\
\text { attempts } \\
(A o)\end{array}$ & $\begin{array}{c}\text { Successful } \\
\text { nestings } \\
(N o)\end{array}$ & $\begin{array}{l}\text { Effort } \\
\text { (\% of } \\
\text { days) }\end{array}$ & $\begin{array}{l}\text { Nesting } \\
\text { success } \\
(\hat{r})\end{array}$ & $\begin{array}{c}\text { Total est. no. } \\
\text { of nest } \\
\text { attempts }\end{array}$ & $\begin{array}{l}\text { Total est. no. } \\
\text { of successful } \\
\text { nestings }\end{array}$ & $\begin{array}{c}\text { No. of } \\
\text { turtles } \\
(\hat{m}=3.03)\end{array}$ \\
\hline 1999 & All year & 12 & 12379 & - & 93.6 & - & 12996 & - & \\
\hline 2000 & All year & 12 & 5977 & 2398 & 85.6 & 0.40 & 6982 & 2801 & 924 \\
\hline 2001 & All year & 12 & 14547 & 7184 & 86.5 & 0.49 & 16977 & 8384 & 2767 \\
\hline 2002 & All year & 12 & 8688 & 4390 & 90.5 & 0.51 & 9890 & 4997 & 1649 \\
\hline 2003 & All year & 12 & 18449 & 9536 & 95.1 & 0.52 & 19691 & 10178 & 3359 \\
\hline 2004 & All year & 12 & 18635 & 9574 & 96.5 & 0.51 & 19260 & 9895 & 3266 \\
\hline 2005 & All year & 12 & 30924 & 15818 & 90.4 & 0.51 & 34514 & 17654 & 5827 \\
\hline 2006 & All year & 12 & 29087 & 14264 & 91.0 & 0.49 & 32057 & 15720 & 5188 \\
\hline 2007 & 1 Jan-15 Jun & 6 & 14996 & - & 89.8 & - & 16771 & - & - \\
\hline Total & & 102 & 153682 & 63164 & 91.0 & - & 169138 & 69630 & - \\
\hline Annua & verage & & & & 91.0 & 0.49 & 19046 & 9947 & 3283 \\
\hline $\mathrm{SD}$ & & & & & 3.6 & 0.04 & 9851 & 5335 & 1761 \\
\hline \multicolumn{10}{|c|}{ Incomplete additional sampling } \\
\hline 2009 & 1 Aug-31 Dec & 5 & 4869 & - & 100.0 & - & 4869 & - & - \\
\hline 2010 & 1 Jan-30 Sep & 9 & 13739 & - & 99.9 & - & 13786 & - & - \\
\hline 2011 & 5 Apr-31 May & 2 & 6663 & - & 100.0 & - & 6663 & - & - \\
\hline 2012 & No sampling & 0 & - & - & - & - & - & - & - \\
\hline 2013 & 1 Jun-31 Dec & 7 & 2230 & - & 69.2 & - & 9792 & - & - \\
\hline 2014 & $\begin{array}{c}1 \text { Jan-30 Apr and } \\
1 \text { Oct-31 Dec }\end{array}$ & 8 & 3440 & - & 73.6 & - & 8616 & - & - \\
\hline Total & & 31 & 30941 & - & - & - & 43726 & - & - \\
\hline
\end{tabular}

needs to be treated as an estimated parameter, and further calculations based on this value must be treated with caution.

\section{Missing data}

Because it was not possible to monitor all 5 beaches each and every day over the study period, particularly during the $8.5 \mathrm{yr}$ period of intensive monitoring, there were occasional days when there was no patrolling effort. To avoid confusing past tracks from missed days, when the patrolling started again, patrollers only counted the last night's tracks, assessing track freshness based on signs of track erosion from wind, tide, and/or rain. We recognise that depending on the observers' experience, nesting density, and past weather conditions, the track count for the last night can be either overestimated (by including tracks from more than the last night) or underesti- mated (by assigning some heavily eroded tracks from the last night to previous nights). We assumed in this study that these are random errors that will not affect the global trend and conclusions over the years.

Gaps in time series of nesting activity were interpolated following the method used by, and employing the same dataset produced by, Dalleau et al. (2012) for the period 1999 to 2010.

\section{Data management and simplification}

A casual evaluation of the data from the 5 adjacent Itsamia nesting beaches indicated no differences in seasonal trends or other nesting behaviour on individual beaches. Given that the 5 beaches are contiguous and of comparable geophysical characteristics but are clearly separated from other nesting beaches at Moheli, it was assumed that these 5 beaches function as 1 'mega' beach. Hence, to reduce the com- 
plexity of the analyses, the 5 adjacent Itsamia nesting beaches were treated functionally as 1 nesting beach. In addition, it was assumed that the relationship between tracks and successful nestings that were made during nights with no monitoring was comparable to the relationship from recorded data.

\section{Calculation of nesting indices}

The monitoring protocol allowed the calculation of nesting success rate $(\hat{r})$, the ratio between the total number of successful nestings (No), and the total number of nest attempts $(\mathrm{Ao})$ observed during a nesting season:

$$
\hat{r}=\frac{N o}{A o}
$$

Hence, the total number of successful nests per season was estimated as the total number of nest attempts multiplied by the rate of nesting success, $\hat{r}$; the total number of nest attempts, in turn, was estimated by including an extrapolation of missing data using the method of Dalleau et al. (2012). To estimate the total number of females nesting per season, we divided the total number of successful nests per season by the average number of successful nestings per female per season $(\hat{m})$. As there is no robust value of $\hat{m}$ for Itsamia beaches, we used the value from Saziley beach (Mayotte), an intensively studied green turtle nesting beach similar to Itsamia beaches in structure and about $150 \mathrm{~km}$ from Itsamia. $\hat{\mathrm{m}}$ at Saziley was $3.03(\mathrm{SD}=0.37)$ (Bourjea et al. 2007a; see 'Discussion' for justification of this choice).

\section{Data and trend analysis}

The trend in annual number of track counts of nesting green turtles at the Itsamia beaches was assessed using an additive model. A time series of monthly track counts from 1999 to 2006 was decomposed in smooth functions for the seasonal and trend features in a generalized additive mixed model (GAMM), using the gamm function of the mgcv R package (version 1.8.4, Wood 2006). GAMMs are semi-parametric generalized linear models, where the linear predictor depends on initially unknown smooth functions and takes into account the uncertainty induced by both random effects and residual variability. A GAMM can be expressed as a combination between a generalized additive model (GAM) and a linear mixed model, the latter being exploited to fit the correlation structures in the model residuals to account for the autocorrelation in the data. GAMM allows a flexible specification of the link functions and error as well as the functional form of each predictor included in the regression model. This method is widely used for the decomposition of complex time series (Bjorndal et al. 1999) and is sometimes favoured over LOWESS smoothing methods (i.e. locally weighted scatterplots smoothing). For comparison, classic seasonal decomposition of time series by loess (Cleveland et al. 1990) has been used to investigate marine turtle nesting trends (Chaloupka 2001, Lauret-Stepler et al. 2007) and was also applied to our data set, yielding results similar to the GAMM analysis (see Fig. S1 in the Supplement, available at www.int-res.com/articles/ suppl/n027p265_supp.pdf, for details).

The time series was decomposed into 2 smooth functions applied respectively to 2 covariates: the month of the year and the time elapsed since January 1999 in months. A random effect term and a residual term also affected the response variable. Smooth functions were set to a cyclic smoothing spline and to a cubic smoothing spline for the trend of the covariate. Finally, an autoregressive seasonal effect of order 1 (nested within each year) was added to the model to account for residual autocorrelations. This model was compared via a generalized likelihood ratio test (ANOVA) to a model containing only the seasonal component (see Table S1 in the Supplement). Using the trend predicted by this model, we estimated the increase of the predicted monthly nesting attempts by calculating the percentage of increase between the fitted value at the beginning of 1999 and the end of 2006. All time series modeling procedures, regression analysis, and statistical tests used here were implemented using the statistical analysis program $\mathrm{R}$ version 3.1.1 (R Core Team 2013).

In addition to the regular beach monitoring from 1999 to 2007, opportunistic monitoring was carried out from August 2009 until 31 December 2014. This allowed follow-up evaluation on the previous $8 \mathrm{yr}$ trend, and although statistically robust analysis of the subsequent $5 \mathrm{yr}$ of data was not possible, the data provided a greater long-term view of nesting activity at Itsamia.

\section{RESULTS}

\section{Monitoring, seasonality, and nesting indices}

Over the 1999-2007 monitoring period, track counts were available for an average of $91.0 \%$ of the days of each year $(\mathrm{SD}=3.6 \%)$, varying from a mini- 
mum of $85.6 \%$ in 2000 to a maximum of $96.5 \%$ in 2004 (Table 1). During these years, there was no clear pattern for missing data, which were distributed over the entire data set. A total of 153682 nesting attempts were recorded, and when missing data were estimated, this corresponded to a total of 169138 estimated nesting attempts (Table 1). The monthly time series of estimated nesting attempts shows strong variation in the total number of nesting attempts from year to year (Fig. 2). The median number of estimated nesting attempts per month from 1 January 1999 to 15 June 2007 shows a peak during the early austral winter from March through August (Fig. 3), with the highest average estimated values in May (2265 nesting attempts, SD $=994, \mathrm{n}=9$ ), and drops during the period from November to February, with the lowest in December, yielding an average of 993 nesting attempts for this month $(\mathrm{SD}=679, \mathrm{n}=8)$. Overall nesting success for the $7 \mathrm{yr}$ period 2000 to 2006 was estimated at $\hat{r}=0.49(\mathrm{SD}=0.04$; Table 1$)$. For this period, 63164 successful nests were recorded, and when using estimates from missing data, there were 69630 successful nests during this period (Table 1).

Using the average number of successful nests per season per female from Saziley beach, Mayotte $(\hat{m}=$ $3.03)$, the average number of nesting females estimated for the 5 combined Itsamia beaches per season was 3283 (SD = 1760.8), with yearly averages that varied between 924 females in 2000 and 5827 in 2005 (Table 1). The overall average number of nesters per season corresponds to a seasonal average of 2014 nesters per kilometre of beach. However, these values are not meant to be taken as precise estimates but rather as an order of magnitude. The large standard deviations observed for both average number of nesting attempts per season and total number of nesting females per season are due to important increases in the number of nesting attempts from 2000 to 2006 as well as the large amount of yearly variation mentioned above (Table 1 ).

The more recent dataset (2009 to 2014) includes 31 mo of beach monitoring from this $6 \mathrm{yr}$ period, irregularly spread along the years, with especially low sampling efforts in 2013 and 2014 (Table 1, Fig. 2). During this period, only nesting attempts were recorded, and in general, the monitoring effort was focused close to the seasonal peak in nesting (2010, 2011, and 2013). The results indicate that the 2010 nesting season had low numbers of nestings (e.g. May 2010 had 1664 estimated nesting attempts), while 2011 and 2013 showed much higher numbers of nestings during the peak (e.g. May 2011 had 3404, and June 2013 had 3086; Fig. 1).

\section{Long-term trend in nesting attempts}

The GAM regression model (see Table $\mathrm{S} 1$ in the Supplement) embedded in the GAMM, including both trend and seasonal nonparametric smooth fits, yielded an overall 0.66 adjusted $\mathrm{R}^{2}$, while trend and

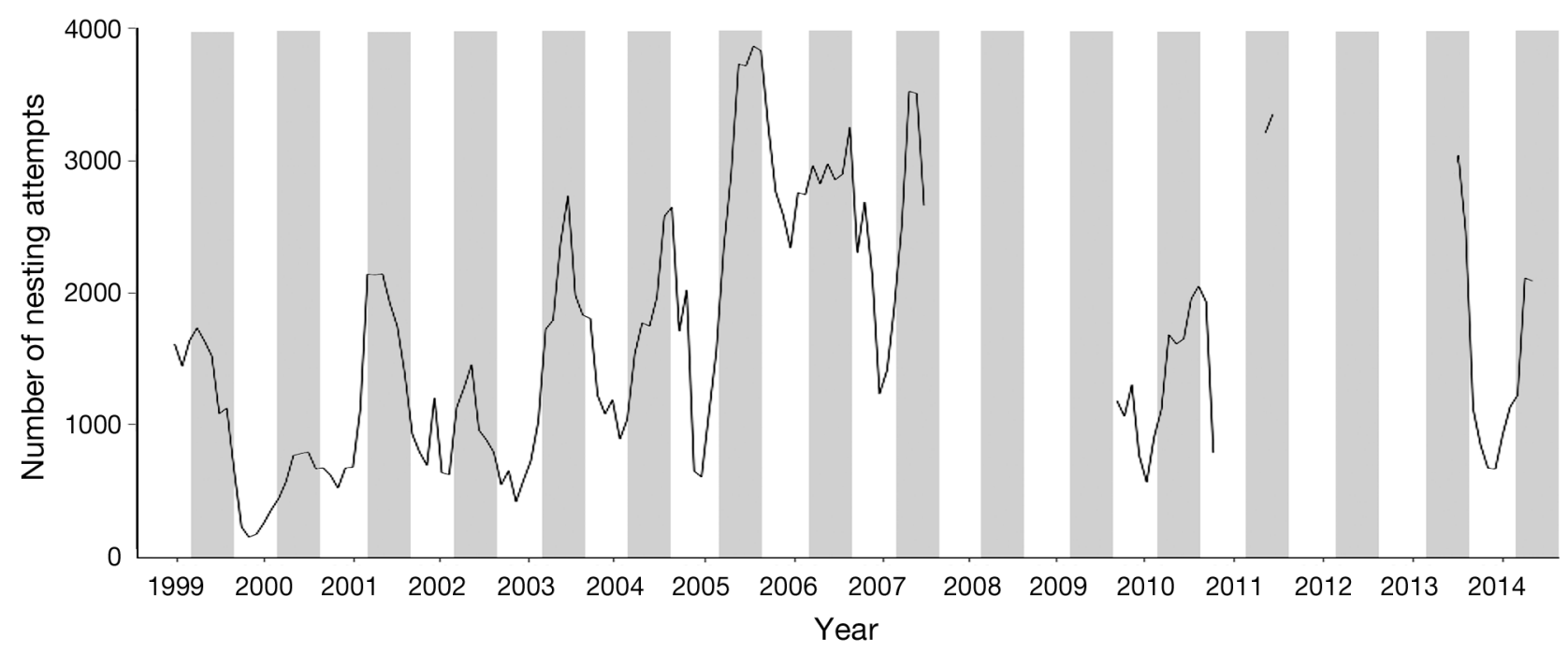

Fig. 2. Monthly time series of female green turtle nesting attempts (based on recorded tracks) on Itsamia beaches, Moheli (January 1999 to December 2014), after interpolation of missing values on daily time series; see Table 1 for details. Grey bar indicates the peak nesting period (March to August) 


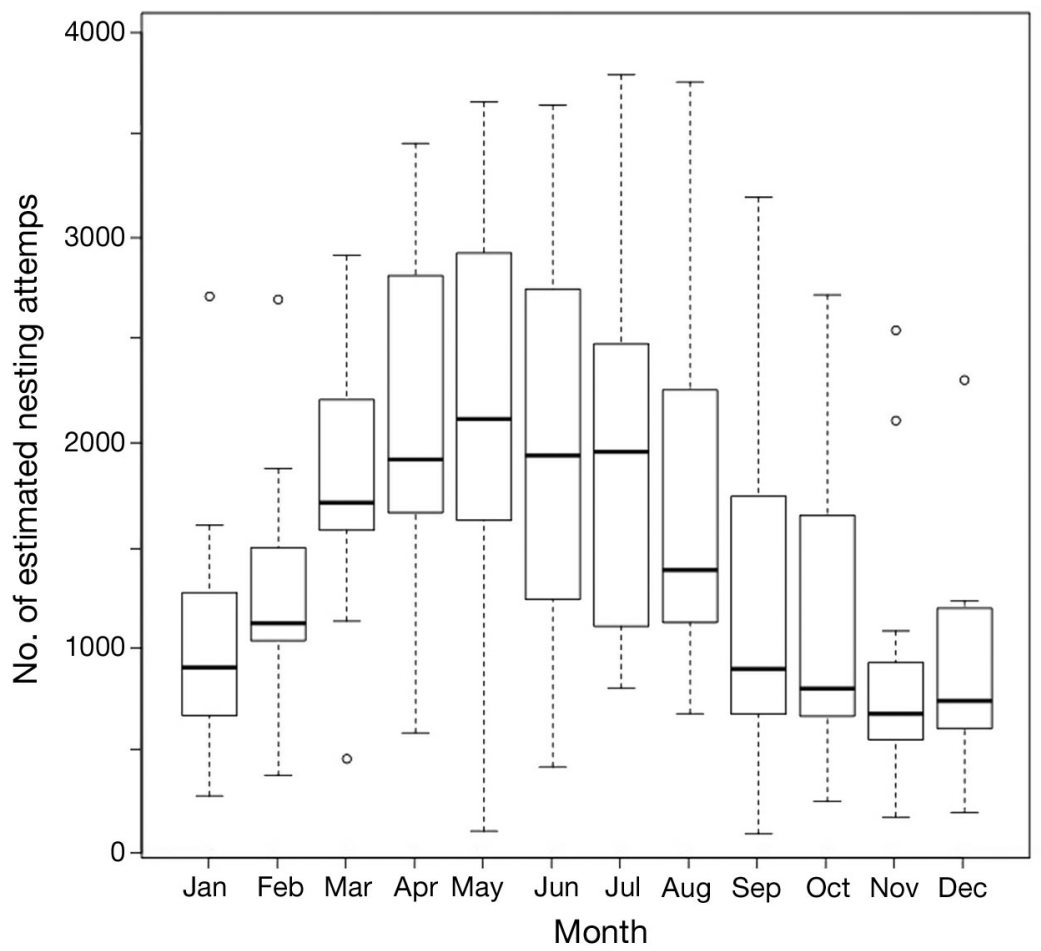

Fig. 3. Box and whisker plot of the monthly average number of estimated nesting attempts (tracks) on the 5 contiguous Itsamia beaches, Moheli, Comoros Archipelago, over the period from January 1999 through December 2014, based on daily monitoring until 2007 and irregular monitoring from 2007 to 2014. Thick horizontal line in each box: 50th percentile (median) of number of tracks for each month; upper and lower boundaries of each box: 75th and 25th percentiles, respectively; top and bottom of the whiskers: 90th and 10th percentiles, respectively; circles above or below the whiskers: extreme outliers

seasonal smooth terms were both significantly affected by the number of tracks per month $(F=6.072$, $\mathrm{p}=0.003$ and $F=4.293, \mathrm{p}<0.0001$, respectively).

Trend over the time series for monthly nesting attempts was extracted. The fitted smooth of the predicted values using the trend component alone is shown in Fig. 4. This prediction of the trend contribution to the data was established under the assumption that seasonal and trend splines did not interact. Given the length of the study period, it is reasonable to assume that no significant change in the seasonal term had occurred over this $8.5 \mathrm{yr}$ period. Confidence interval bands showed a widening at the beginning and end of the sampling period, estimates of the trend being less constrained where fewer data were available (Fig. 4). Using the fitted value of the model, we estimated that the number of nesting attempts increased by $226 \%$ from 1999 to mid-2007 (143 to $391 \%$ based on fitted trend with $95 \%$ confidence intervals).

\section{DISCUSSION}

\section{Seasonality of nesting effort}

Green turtles nest all year long at Moheli (Figs. 2 \& 3); nonetheless, as at other nesting colonies, both regionally and worldwide (Bjorndal et al. 1999, Chaloupka 2001, Godley et al. 2001, Limpus et al. 2001, 2003, Bourjea et al. 2007a, Lauret-Stepler et al. 2007), they exhibit a distinct seasonal peak in nesting activity as well as strong variation in the total number of nesting attempts from year to year, a phenomenon that is usual and often documented in studies of green turtle nesting (see review for the western Indian Ocean in Dalleau et al. 2012). Such seasonal variation could be due to environmental stochasticity at foraging grounds and the relatively low position of the green turtle in the food chain (Broderick et al. 2001, Chaloupka et al. 2008b). The nesting peak at Moheli takes place during the austral winter, from March to August, which coincides with the dry season at this island. A comparable pattern is documented for other nesting grounds in the region, such as Mayotte (Bourjea et al. 2007a), Grande Glorieuse (Lauret-Stepler et al. 2007), Aldabra Atoll (Mortimer 2012), and D'Arros Island in the Amirantes (Mortimer et al. 2011b), as well as in Mozambique (Garnier et al. 2012).

Interestingly, Dalleau et al. (2012) demonstrated synchrony in nesting peaks between Moheli (Itsamia) and other rookeries in the northern part of the SWIO (e.g. Aldabra, Glorieuses, and Mayotte) but not with more eastern and southern rookeries (Tromelin and Europa). In fact, as shown by Lauret-Stepler et al. (2007) and Dalleau et al. (2012), not all nesting colonies in the SWIO exhibit the same seasonality; there is a clear peak in nesting during the wet season (austral summer) for Europa, in the south of the Mozambique Channel, and Tromelin, off the east coast of Madagascar. These marked differences in nesting seasonality are remarkable, for they occur over a relatively small geographic area and in populations that are thought to make breeding migrations of more than $1000 \mathrm{~km}$ in the SWIO (Hughes 1982, Le Gall \& Hughes 1987). Thus, individual turtles may occur together in the same non-breeding areas, even 


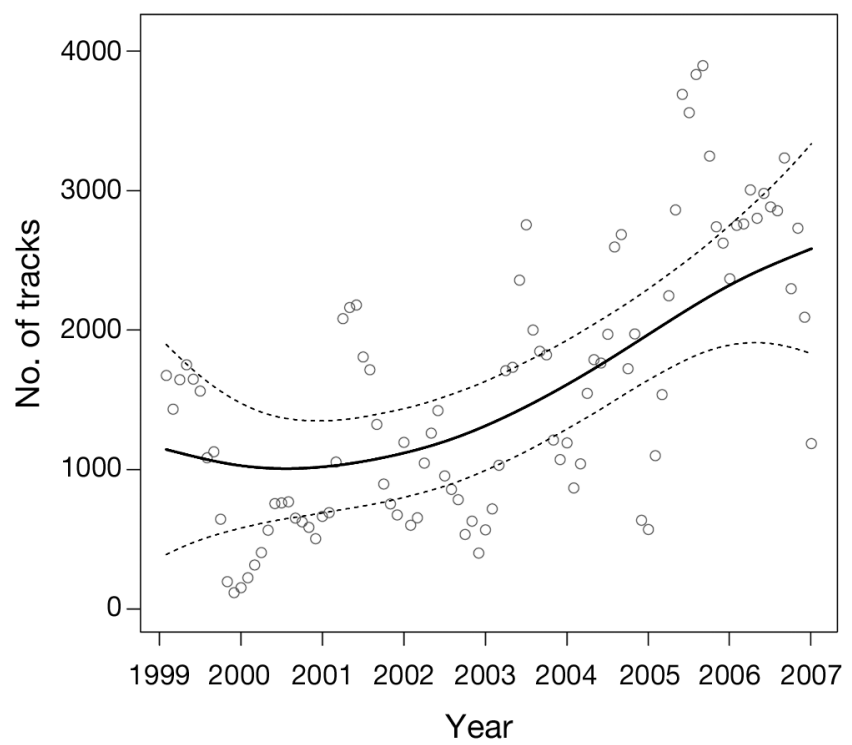

Fig. 4. Fitted trend component in Itsamia beaches monthly track counts from 1999 to mid-2007, Moheli, Comoros Archipelago. Solid line: fitted smooth (cubic smoothing spline) of the predicted number of tracks per month from the generalized additive mixed model trend component; dashed lines: $95 \%$ confidence intervals; grey open circles: estimated number of tracks

though they have very different seasonality in nesting. Nonetheless, oceanographic conditions, such as SST, are thought to have major impacts on green turtle nesting seasonality in the SWIO (Dalleau et al. 2012).

\section{Critical parameters in the nesting ecology of Moheli green turtles}

The estimated average seasonal nesting success calculated for 2000 to 2006 varied from 0.40 to 0.52 over the study period, with a $7 \mathrm{yr}$ average of 0.49 $(\mathrm{SD}=0.04$; Table 1$)$ and a clear increasing trend over the period that could influence other trends. Although records of successful nests were estimated from observations of nesting spoor and not from direct confirmation of the presence of eggs, the annual values for nesting success, with the exception of the first year, are remarkably similar. This indicates either that these relatively constant estimates are reliable or that there is a constant error in the estimation, which is less probable. The $7 \mathrm{yr}$ average nesting success for Moheli is lower than the average value reported for some other nesting sites in the SWIO, such as Mayotte $(0.77, \mathrm{SD}=0.05$; Bourjea et al. 2007a), Europa (0.66, SD = 0.01; Le Gall 1988), and Tromelin $(0.56, \mathrm{SD}=0.00 ;$ Le Gall 1988). It should be noted that these other nesting success estimations for the SWIO were calculated from tagging and recapture data that may overestimate this parameter by missing unsuccessful nesting attempts while patrolling. Values for nesting success from outside the region, estimated by using track counts, can be either lower than that for Moheli, such as 0.33 at Ascension Island ( $S D=0.08$; Godley et al. 2001), or higher, such as 0.75 at Vamizi, Mozambique (Garnier et al. 2012). Various environmental variables, such as density of nesters on the beach, rain, tide, and condition of the subsurface sand may affect the success of nesting attempts (Limpus et al. 2003); physiological and behavioural conditions of the nesting females, as well as nesting experience, may also affect nesting success (Perrault et al. 2012).

To estimate the number of nesting females using track counts, it is necessary to know the average number of nests per season per female. The average value from Saziley beach, Mayotte (3.03), was thought to be the best estimate. Added to the fact that Moheli and Mayotte are part of the same genetic stock (Bourjea et al. 2007b), the validity of this value is also supported by the comparable mean number of nestings per female for other islands in the SWIO region: Tromelin Island, with a single beach isolated on a remote oceanic island and thus with highly reduced chances of immigration or emigration during the nesting season, was somewhat higher $(\hat{m}=$ $3.50)$, and Europa Island was slightly lower $(\hat{m}=2.80$; Le Gall 1988). These values are also similar to those from other sites in other regions, such as Ascension Island ( $\hat{m}=3.0$; Mortimer \& Carr, 1987) and Tortuguero, Costa Rica ( $\hat{m}=2.8$; Carr et al. 1978).

\section{Trend in nesting attempts}

The increase from 1999 to mid-2007 (more than $8 \mathrm{yr}$ ) in the number of nesting attempts is remarkably high: $226 \%$ (with $95 \%$ confidence intervals of 143 to $391 \%$, i.e. 0.17 to 0.49 annual growth rates). However, this rapidly increasing trend does not necessarily mean that the number of nesting females increased at this same rate; several things other than population increase could contribute to this marked increase in nesting activity at the Itsamia beaches. An increase in the average number of nests per female per season would contribute to this trend. Additionally, a change in field techniques, particularly the criteria for scoring a new track from an old or a change in scoring successful nestings, could contribute to a perceived increase in successful nesting 
attempts (Schroeder \& Murphy 1999); however, there is no evidence for such a methodological change, for the ratio of successful to total nesting attempts remains relatively stable after the first year (Table 1). Even if methods of estimating the number of nesting attempts from one study to another varied, the annual increase in the estimated number of nesting females at Itsamia is much greater than that for other nesting sites in the SWIO such as Mayotte (Bourjea et al. 2007a) or Europa (Lauret-Stepler et al. 2007). On Aldabra for instance, Mortimer et al. (2011a) estimated an increase of the annual number of nesters from 500 to $800 \%$ over 40 yr (i.e. 0.12 to 0.20 annual growth rates). Outside the region, at major green turtle rookeries in the Atlantic and Pacific, population annual growth rates range between 0.038 and 0.139 (Chaloupka et al. 2008a). These increases also correspond to sites where conservation measures were introduced and enforced for at least $25 \mathrm{yr}$, with the respective green turtle stocks recovering from serious depletion primarily due to over-exploitation of eggs and turtles (Ehrhart \& Bagley 1999, Chaloupka \& Limpus 2001, Balazs \& Chaloupka 2004, Troëng \& Rankin 2005, Chaloupka et al. 2008a).

However, apparent trends in marine turtle nesting activity based on just 8 yr of data must be interpreted with care. Marked seasonal variation in numbers of nesters can give the appearance of a long-term trend. For example, annual numbers of nesting green turtles on Heron Island, Great Barrier Reef, showed what appeared to be an increasing trend over $7 \mathrm{yr}$, but with additional years of sampling, the numbers were not consistent with the long-term trend (Limpus 2007). In the present case, additional data gathered after the 8 yr trend show several values from peak nesting periods of different seasons (Fig. 2). For 2010 and 2014, there are values at the middle of the spread, and for 2011 and 2013, the peak nesting values approach the highest value recorded in 2005 . Taken together, the data between 1999 and 2014, from both regular monitoring and irregular monitoring, indicate that there was an increasing trend for the first decade followed by a leveling off.

\section{Why such an apparently rapid increase in nesting activity at Itsamia?}

First, it is important to note that the number of years of data available for the statistically robust trend analysis at Itsamia was 8 yr. For instance, in the case of the Raine Island study, $31 \mathrm{yr}$ of data were analysed and showed a higher rate of increase for the first $10 \mathrm{yr}$ of monitoring followed by a lower rate of increase in subsequent years (Chaloupka et al. 2008a), a deceleration in the rate of increase comparable with what Itsamia data show.

Several factors may be involved. The recent history of turtle exploitation at the Itsamia beaches may be relevant. Until 1980, these beaches were relatively isolated and accessible primarily to the people of Itsamia village. Because of religious beliefs, these people did not, and do not, eat or kill marine turtles. In 1972, the Itsamia beaches were found to have the largest concentration of nesting green turtles in Moheli and all of Comoros, but it was also estimated for the same year, from preliminary observations, that about $10 \%$ of the total nesting green turtles were killed at Moheli, including occasionally at Itsamia beaches (Frazier 1985). In 1983, a bilateral aid program with Japan resulted in small, motorised fishing boats (called Japawas) becoming available in Comoros. As a result, fishermen from Anjouan and Grande Comore could travel relatively quickly and easily to the coast of Moheli, allowing them to exploit nesting green turtles from the Itsamia beaches. As many as 10 to 30 nesters were caught per day, and this continued until 1991, when the Itsamia villagers decided to deny access to fishermen from Anjouan and Grande Comore to Itsamia beaches (A. M'Soili pers. obs.). Since that date, poaching decreased until the middle of the 1990s, and there have been only a few reports of turtle poaching from these beaches since then (A. M'Soili pers. obs.). Hence, after an extended period of low, or no, exploitation, Itsamia beaches were subjected to intense exploitation from 1983 to the early 1990s. Since green turtles require at least 25 to $30 \mathrm{yr}$ to reach sexual maturity (Limpus \& Walter 1980), even during the period of intense exploitation at Itsamia, there should have been significant recruitment into the nesting population from nesting that had occurred before 1983. Hence, once intense exploitation was stopped in 1991, the nesting population, which is comprised of both new recruits and returning nesters that survived the previous nesting season, would have been expected to grow relatively rapidly.

Immigration of nesting females that might otherwise have nested at other beaches around Itsamia, or elsewhere in the Comoros or the region, could also contribute to an increase in the number of nesting females at the Itsamia beaches. As the Itsamia beaches and offshore waters now enjoy protection, while other nearby nesting sites on Moheli and other beaches in Comoros are subject to continuing perturbation, reproductive turtles could be driven out of the 
disturbed areas to the safer Itsamia beaches. Hence, increased immigration of nesting females to Itsamia, with an increase in numbers at this important rookery, could occur, although the population size of the management unit may not experience an increase. An increase in the number of nests per female per season could also result in a significant increase in annual nesting activity; this could be tied to maturational changes with increased fecundity and/or enhanced forage conditions, with improved reproductive output (Limpus \& Chaloupka 1997).

Unfortunately, the dataset usable for a statistically robust trend stops at 2007. The question remains what the real situation in the 2007-2014 period was. We know that the nesting activity was still high (Fig. 2), although not systematically quantified, so the available observations do not allow robust comparisons with the datasets based on regular monitoring used in this study, and it is almost impossible to estimate if the annual increase in nesting attempts was comparable to the 1999-2007 period, was still the same, or if it slowed down.

\section{Regional importance of Itsamia nesting beaches}

With the results of the present study, there are now reliable estimates of the number of nesting green turtles per season for several important rookeries in the SWIO. Prior to this study, Europa Island was regarded as hosting the largest colony, with between 3000 and 10000 individuals nesting per season (Le Gall 1988), and recent data indicate that the annual nesting numbers have increased from the 1980s (J. Bourjea pers. obs.). Aldabra is next, with 3100 to 5225 (Mortimer et al. 2011a). Mayotte has more than 2000 annual nesters on just the 2 most important nesting beaches on the island (Bourjea et al. 2007a). Tromelin has between 1000 and 3000 (Le Gall 1988), and recent data indicate that this number is stable (Derville et al. in press). Grande Glorieuse had some 1480 nesting females on just $26 \%$ of the suitable nesting sites (Lauret-Stepler et al. 2007). In comparison, just the 5 Itsamia beaches of Moheli clearly provide a significant component to the total number of annual nesters in the region, with more than 5000 nesters per season estimated. Considering scores of other nesting beaches on Moheli, particularly the islands off the southern coast (Frazier 1985, F. Beudard pers. obs.), the total nesting population at Moheli is one of the largest in the SWIO; it could be second only to Europa. Including other nesting sites in the Republic of Seychelles in addition to Aldabra (particularly Cosmoledo Atoll and the Amirantes Islands; Mortimer et al. 2011b), as well as nesting beaches in Mozambique (Bazaruto, Primeiras, and Segundas; Garnier et al. 2012), East Africa (Tanzania and Kenya; Frazier 1984), and Iranja Kely island in Madagascar (Bourjea et al. 2006), it is clear that the SWIO is one of the most important regions in the world for nesting green turtles.

Acknowledgements. This paper is dedicated to Habibou and Absoir for the fantastic work they did for the conservation of marine turtles at Itsamia over many years. In late 2011, the sea took them too soon. The authors thank the Regional Environment Programme of the Indian Ocean Commission (PRE-COI), Programme des Nations Unies pour le Développement (PNUD), PROGECO, European Union via the POCT Réunion fund, France, and Région Réunion for the financial support for field work. We are also most grateful to the members of ADSEI for their incredible work in the field and the enthusiasm they developed for the conservation of marine turtles and, especially, the marine ecosystem at Itsamia. We also thank the Kélonia and Ifremer teams as well as all students who worked at Itsamia over the last 17 yr. And lastly, we thank 3 anonymous reviewers and the editor for improving the manuscript.

\section{LITERATURE CITED}

Balazs GH, Chaloupka M (2004) Thirty-year recovery trend in the once depleted Hawaiian green sea turtle stock. Biol Conserv 117:491-498

Bjorndal KA, Wetherall JA, Bolten AB, Mortimer JA (1999) Twenty-six years of green turtle nesting at Tortuguero, Costa Rica: an encouraging trend. Conserv Biol 13: 126-134

Bourjea J, Ciccione S, Rantsimbazafy R (2006) Marine turtles surveys in Nosy Iranja Kely, north-western Madagascar. West Ind Ocean J Mar Sci 5:209-212

Bourjea J, Frappier J, Quillard M, Ciccione S, Roos D, Hughes G, Grizel H (2007a) Mayotte Island: another important green turtle nesting site in the southwest Indian Ocean. Endang Species Res 3:273-282

Bourjea J, Lapègue S, Gagnevin L, Broderick D and others (2007b) Phylogeography of the green turtle, Chelonia mydas, in the Southwest Indian Ocean. Mol Ecol 16:175-186

Bourjea J, Muths D, Garnier J, Mortimer JA and others (in press) New genetic evidence can enhance perspectives on regional management: the case of the green turtle in the south west Indian Ocean. Conserv Genet, doi:10. 1007/s10592-015-0723-3

Broderick AC, Godley BJ, Hays GC (2001) Trophic status drives interannual variability in nesting numbers of marine turtles. Proc R Soc B 268:1481-1487

Carr A, Carr MH, Meylan AB (1978) The ecology and migrations of sea turtles, 7. The west Caribbean green turtle colony. Bull Am Mus Nat Hist 162:1-46

> Chaloupka M (2001) Historical trends, seasonality and spatial synchrony in green sea turtle egg production. Biol Conserv 101:263-279

> Chaloupka M, Limpus CJ (2001) Trends in the abundance of sea turtles resident in southern Great Barrier Reef waters. Biol Conserv 102:235-249 
Chaloupka M, Bjorndal K, Balazs G, Bolten A and others (2008a) Encouraging outlook for recovery of a once severely exploited marine megaherbivore and restoration of its ecological function. Glob Ecol Biogeogr 17:297-304

Chaloupka M, Kamezaki N, Limpus C (2008b) Is climate change affecting the population dynamics of the endangered Pacific loggerhead sea turtle? J Exp Mar Biol Ecol 356:136-143

Ciccione S, Bourjea J (2006) Nesting of green turtles in Saint Leu, Réunion Island. Mar Turtle Newsl 112:1-3

Cleveland RB, Cleveland WS, McRae JE, Terpenning P (1990) STL: a seasonal trend decomposition procedure based on Loess. J Off Stat 6:3-73

Dalleau M, Ciccione S, Mortimer JA, Garnier J, Benhamou S, Bourjea J (2012) Nesting phenology of marine turtles: insights from a regional comparative analysis on green turtle (Chelonia mydas). PLoS ONE 7:e46920

Derville S, Jean C, Dalleau M, Le Gall JY, Ciccione S, Bourjea $\mathrm{J}$ (in press) Long term monitoring of green turtle nesting on Tromelin Island demonstrates stable reproduction and population parameters. Chelonian Conserv Biol

Ehrhart LM, Bagley DA (1999) Marine turtle nesting at the Archie Carr NWR: long-term rising trend culminates in record high nest production in 1998. Fla Sci 62:34-35

Frazier J (1971) Observations on sea turtles on Aldabra Atoll. Philos Trans R Soc Lond B 260:373-410

> Frazier J (1975) Marine turtles of the western Indian Ocean. Oryx 13:164-175

Frazier J (1980) Exploitation of marine turtles in the Indian Ocean. Hum Ecol 8:329-370

Frazier J (1982) Status of sea turtles in the central western Indian Ocean. In: Bjorndal K (ed) Biology and conservation of sea turtles. Smithsonian Institution Press, Washington, DC, p 385-389

Frazier J (1984) Marine turtles in the Seychelles and adjacent territories. In: Stoddart DR (ed) Biogeography and ecology of the Seychelles Islands. W Junk, The Hague, p 417-468

Frazier J (1985) Marine turtles in the Comoro Archipelago. North-Holland, Amsterdam

Frazier J (2012) Nest and track surveys. In: McDiarmid RW, Foster MS, Guyer C, Gibbons JW, Chernoff N (eds) Reptile biodiversity: standard methods for inventory and monitoring. University of California Press, Berkeley, CA, p 260-264

Fretey J, Fourmy J (1996) The status of sea turtle conservation in French territories of the Indian Ocean: Mayotte. In: Humphrey SL, Salm RV (eds) Status of sea turtle conservation in the western Indian Ocean. UNEP Regional Seas Reports and Studies No. 165. IUCN/UNEP, Nairobi, p 133-143

> Garnier J, Hill N, Guissamulo A, Silva I, Debney A, Godley B (2012) Status of marine turtles in the northern Querimbas (Mozambique). Oryx 46:359-367

Godley BJ, Broderick AC, Hays GC (2001) Nesting of green turtles (Chelonia mydas) at Ascension Island, South Atlantic. Biol Conserv 97:151-158

Hughes GR (1973) The sea turtles of south east Africa. PhD dissertation. University of Natal, Durban

Hughes GR (1982) Conservation of sea turtles in the southern African region. In: Bjorndal K (ed) Biology and conservation of sea turtles. Smithsonian Institution Press, Washington, DC, p 397-404

Lauret-Stepler M, Bourjea J, Roos D, Pelletier D, Ryan PG,
Ciccione S, Grizel H (2007) Reproductive seasonality and trend of Chelonia mydas in the SW Indian Ocean: a $20 \mathrm{yr}$ study based on track counts. Endang Species Res 3: 217-227

Le Gall JY (1988) Biologie et évaluation des populations de tortues vertes Chelonia mydas des atolls Tromelin et Europa (Océan Indien S.O.). Mésogée 48:33-42

- Le Gall JY, Hughes GR (1987) Migrations de la tortue verte Chelonia mydas dans l'Océan Indien sud-ouest observées à partir des marquages sur les sites de ponte Europa et Tromelin (1970-1985). Amphib-Reptilia 8: 277-282

Le Gall JY, Bosc P, Château D, Taquet M (1986) Estimation du nombre de tortues vertes femelles adultes Chelonia mydas par saison de ponte a Tromelin et Europa (Océan Indien) (1973-1985). Oceanogr Trop 21:3-22

Lilette V (2007) Conservation et patrimonialisation de la tortue marine dans le sud ouest de l'océan Indien. Thèse de Doctorat, University of La Réunion

Limpus CJ (2007) A biological review of Australian marine turtles. 2. Green turtle Chelonia mydas (Linnaeus). Environmental Protection Agency, Queensland

Limpus C, Chaloupka M (1997). Nonparametric regression modelling of green sea turtle growth rates (southern Great Barrier Reef). Mar Ecol Prog Ser 149:23-34

Limpus CJ, Walter DG (1980) The growth of immature green turtles (Chelonia mydas) under natural conditions. Herpetologica 36:162-165

Limpus CJ, Carter D, Hamann M (2001) The green turtle, Chelonia mydas, in Queensland, Australia: the Bramble Cay rookery in the 1979-1980 breeding season. Chelonian Conserv Biol 4:34-46

Limpus CJ, Miller JD, Parmenter CJ, Limpus DJ (2003) The green turtle, Chelonia mydas, population of Raine Island and the northern Great Barrier Reef: 1843-2001. Mem Queensl Mus 49:349-440

Mortimer JA (1985) Recovery of green turtles on Aldabra. Oryx 19:146-150

Mortimer JA (2012) Seasonality of green turtle (Chelonia mydas) reproduction at Aldabra Atoll, Seychelles (19802011) in the regional context of the western Indian Ocean. Chelonian Conserv Biol 11:170-181

Mortimer JA, Carr A (1987) Reproduction and migration of the Ascension Island green turtle (Chelonia mydas). Copeia 1987:103-113

Mortimer JA, von Brandis RG, Liljevik A, Chapman R, Collie $\mathrm{J}$ (2011a) Fall and rise of nesting green turtles (Chelonian mydas) at Aldabra Atoll, Seychelles: positive response to four decades of protection (1968-2008). Chelonian Conserv Biol 10:165-176

> Mortimer JA, Camille JC, Boniface N (2011b) Seasonality and status of nesting hawksbill (Eretmochelys imbricata) and green turtles (Chelonia mydas) at D'Arros Island, Amirantes Group, Seychelles. Chelonian Conserv Biol 10:26-33

Perrault JR, Miller DL, Eads E, Johnson C and others (2012) Maternal health status correlates with nest success of leatherback sea turtles (Dermochelys coriacea) from Florida. PLoS ONE 7

R Core Team (2013) R: a language and environment for statistical computing. R Foundation for Statistical Computing, Vienna. www.r-project.org

Schroeder B, Murphy S (1999) Population surveys (ground and aerial) on nesting beaches. In: Eckert KL, Bjorndal 
KA, Abreu-Grobois FA, Donnelly M (eds) Research and management techniques for conservation of sea turtles. Publ No. 4, IUCN Marine Turtle Specialist Group, Washington, DC, p 45-55

Seminoff JA (2004) 2004 IUCN Red List global status assessment: green turtle (Chelonia mydas). IUCN Marine Turtle Specialist Group Review, Gland

Troëng S, Rankin E (2005) Long-term conservation efforts

Editorial responsibility: Jeffrey Seminoff,

La Jolla, California, USA contribute to positive green turtle Chelonia mydas nesting trend at Tortuguero, Costa Rica. Biol Conserv 121: 111-116

- Wallace BP, DiMatteo AD, Bolten AB, Chaloupka MY and others (2011) Global conservation priorities for marine turtles. PLoS ONE 6:e24510

Wood S (2006) Generalized additive models: an introduction with R. Chapman \& Hall/CRC, Boca Raton, FL

Submitted: October 10, 2014; Accepted: February 12, 2015

Proofs received from author(s): April 15, 2015 